\title{
The Impact and Design of the MDGs: Some Reflections
}

\author{
Richard Manning
}

\begin{abstract}
The MDGs appear to have been more influential than most other attempts at international targetsetting in the field of development, at least at the level of international discourse. But has this translated into impact on either development policy or resource allocation, and if so has the impact been constructive or not? And what lessons does this suggest for any future target-setting proposals?
\end{abstract}

\section{Introduction}

The Millennium Declaration of 2000 was a wideranging statement, agreed by all UN members, giving a vision of a fairer and more sustainable future for the world, and in particular for its poorer countries and citizens. The Declaration also set out a number of specific targets to be met by 2015 (or in one case, 2020). These provided the basis for the more detailed structure of the Millennium Development Goals (MDGs), of which the authoritative version was contained in an Annex to a 'Road Map' produced by the Secretary-General in September 2001. This set out the structure of eight Goals, 18 Targets and 48 Indicators that has constituted the MDG framework. This structure was updated following the UN Summit Session of 2005, and now incorporates 21 Targets and 60 Indicators.

It is noteworthy that the Annex to the 'Road Map' was not formally endorsed by the UN membership, but merely described as 'a useful guide' in the relevant Resolution, ${ }^{1}$ and that the subsequent updating has been carried out by the so-called Inter-Agency and Expert Group on the Millennium Development Goal Indicators, a body whose status is pleasingly unclear. ${ }^{2}$

Nevertheless, despite this less than robust formal basis, there can be no doubt that the MDGs have become highly influential at least at the level of international discourse about development. Significant resources are allocated to tracking them; the UN leads the production of annual reports about them, convenes regular Summit Sessions about them, and sponsors an ongoing 'Millennium Campaign'; the World Bank and IMF put together an annual 'Global Monitoring Report' about them; and no G8 summit is complete without some reference to them. A special summit session of the UN General Assembly to review progress will take place in September 2010, and there will be much discussion of a 'big push' to secure the maximum progress on the various Goals by 2015 .

This article asks whether there is evidence that the MDGs have had impact in the 'real world' of choices about development strategy and resource allocation; whether such influence as exists is constructive or not; and what lessons might be drawn for any subsequent attempt to define development Goals on an international level after 2015.

The basic documents of 2000-01 do not specify the purpose of the MDGs. I have argued elsewhere (Manning 2009) that their purpose is 'to encourage sustainable pro-poor development progress and donor support of domestic efforts in this direction', and this article takes this as a core assumption.

\section{Have the MDGs affected development policy or resource allocation?}

It would be as well to make clear at the outset that it is intrinsically hard to separate out the impact of targets from the environment that created them. Thus the MDGs have a strong focus on health 
(three of the eight Goals are health-related) and official development assistance for health has increased rapidly. But health, and particularly child health, has long been a natural focus for the donor community and for development advocates, and it is not easy to distinguish the particular impact of the MDGs. Indeed, in one striking case, it is clear that resourcing decisions had nothing to do with the MDGs as such: thus the Bush Administration, a robust critic of the MDGs, became by far the largest financial supporter of HIV/AIDS programmes, not because of MDG 6 but because of an alliance of interests including the views of core Republican supporters such as the 'Religious Right'.

Recognising the likely limitations of our ability to separate out the impact of the MDGs in a wholly convincing way, let us look at what can be said first about the impact on the donor community and second (but more importantly) at country level.

\subsection{Impact on donors}

Most individual donor governments (and the EU collectively) have made specific and regular use of the MDGs in domestic dialogue about the purpose and effectiveness of development spending. The USA, under the Bush Administration, and Japan, which made no reference at all to the MDGs in their 2003 'ODA Charter', have been important exceptions to this. China is among several donors outside the traditional Development Assistance Committee (DAC) grouping which has also stated that its aid is aimed at supporting local efforts to achieve the MDGs. Most international agencies have also paid much attention to progress or the lack of it against the MDGs, particularly where the agency has a mandate closely relevant to one or more MDG. The Global Fund to Fight AIDS, Tuberculosis and Malaria is a particularly clear example of a funding agency where the MDGs (specifically MDGs 4, 5 and 6) are central to the agency's DNA.

A study of 21 DAC members by Sakiko FukudaParr (see this IDS Bulletin and Fukuda-Parr 2008) however points out that donors' policy documents typically pay considerable attention to issues not explicitly covered in the MDGs, notably in the areas of promoting peace, security and human rights. ${ }^{3}$ These are aspects covered by the Millennium Declaration, but not specifically addressed by the MDGs as such. Some issues that loom large in the MDGs, for example employment, hunger, maternal mortality, child survival, gender equality, social integration and science and technology, were given relatively low attention in these documents. There is still however a solid core of coherence between donor policy statements and the MDGs.

As to whether the existence of the MDGs has affected resource allocation by donors, for the reasons given above it is not possible to give an unambiguous answer. Undoubtedly, the proportion of aid going to the productive sector (not directly covered by the MDGs) has fallen, and the proportion to social sectors (well-covered by the MDGs) has risen. Some donors have, for example, massively increased support of basic education, to the point where there have been concerns expressed about an imbalance of aid spending on education in favour of basic education (after several decades of a pronounced focus on tertiary, and for some donors, on vocational education). This emphasis has very likely been stimulated by the MDG for universal basic education. However, this phenomenon has been limited in practice to a small number of donors, for example the Netherlands and the UK.

Similarly, the MDGs have probably encouraged further concentration on infant and child health, and the linked problems of infectious diseases, and the rise of global funds to tackle immunisation and disease-specific interventions has gone hand-inhand with the development of the MDG philosophy, ${ }^{4}$ even though there is certainly no simple relationship. The MDGs have also had some success in stimulating greater focus among some donors on widely neglected problems such as maternal mortality ${ }^{5}$ (but to date with depressingly little well-documented impact), but nutrition appears to have been a counter example where despite the existence of a clear Target under MDG 1 , little donor focus has been evident. ${ }^{6}$

Some would argue that the MDGs, and their DAC predecessor of 1996, have had a negative impact on donors' thinking through discouraging worthwhile investment in the productive sectors and in infrastructure, none of which are explicitly captured by the way the MDGs are framed (with the exception of water and sanitation - a Target and information communication technologies - an Indicator). This is sometimes seen as a promotion of welfare and aid dependence over growth and self-reliance. 
It is hard to separate out the impact of the MDGs from other factors that have led to significant changes in the share of such sectors in ODA. OECD figures (OECD DAC 2004) show that the share of ODA to agriculture turned down sharply as long ago as the late 1980s - perhaps as a result of the poor experience with ambitious projects for rural development. For energy, where the major decline in share was a decade later, the DAC Goals could have had some relevance, but it is likely that the 'Helsinki Disciplines', which in practice ended tied aid for power stations and other financially viable projects, were more influential. For industry, where there has been a secular decline from the 1980s onwards, liberalisation of the economy is likely to have been as significant as 'MDG thinking'.

Perhaps the most far-reaching and positive influence of the MDGs on donors - although one hard to measure - has been in strengthening the view that if support for aid is to be sustained, measurable progress must be shown in areas that the public in donor countries view as desirable. This is arguably far healthier than the traditional 'establishment-based' model, where aid programmes (other than humanitarian aid) were greeted with a high degree of indifference by the public and most strongly supported by public and private interests with something to gain from the influence of aid in securing either political or commercial advantage. This shift in perception is by no means universal, and knowledge of the MDGs in donor countries is still not widespread, but it has arguably made it harder for governments to 'sell' development aid that does not contribute to real development progress. Organisations such as ONE, with its annual 'DATA' Report, encourage a focus on MDG outcomes as well as on delivery of aid commitments.

\subsection{Impact on developing countries}

While it is historically true that the MDGs owed a great deal to the DAC International

Development Goals, put together very much as a tool for donors to justify continuing investment in aid programmes at a time when they were falling significantly, the ultimate value of the MDGs in changing behaviour and outcomes will depend much more on their impact at country level. It is therefore unfortunate that there is not as yet much accumulated research evidence of the extent of such impact, if any.
Sakiko Fukuda-Parr's study referred to above examined 22 Poverty Reduction Strategies, covering 17 less-developed countries, two other low-income countries and three lower middleincome countries. She found that almost all stated a commitment to the MDGs, but that the focus was quite selective. In some respects, this mirrored the approach of the donors (e.g. serious attention to social sector spending, but little attention to hunger and nutrition, decent work and technology transfer), and in others it differed significantly (a greater focus on economic growth, little attention to democracy, freedom of the media or human rights). Targets were often set for several MDG priorities, Targets often in fact more ambitious than the MDGs and reflecting local results frameworks such as Tanzania's 'Vision 2025'. On the other hand, the calculations supported by the UN Millennium Project of the investment needed to meet the MDGs dependent on public services were not referred to, nor were these fully incorporated into the countries' planning and budgeting.

The United Nations Development Programme (UNDP) conducted its own survey of progress against the MDGs in 30 countries in 2009 (UNDP 2009). This demonstrated the wide variety of situations, some countries (generally the better off, such as Bahrain) making virtually no use of the MDGs as a way of measuring or incentivising progress, but a large number having integrated the MDGs (or often a locally adapted version) into their own development planning.

Indeed, the 'customisation' of the MDGs is a notable feature brought out by the study. Of the 30 countries, ten had added or modified Goals. Thus, for example, Albania, Iraq and Mongolia had added a Goal on good governance and/or fighting corruption; Armenia, Cambodia, Kyrgyzstan and Tajikistan had included eight or nine years of education for all children as modification of Goal 2; and Colombia and Mongolia had added relevant national infectious diseases to Goal 6 . Some 15 countries had added, expanded or modified Targets, and no fewer than 25 had added, expanded or modified Indicators, for example to reflect national poverty lines. Such steps imply at least a measure of local ownership of the MDGs among a wide variety of countries.

Even where the government's planning documents are not built around the MDGs as such, MDG-type 
outcome Targets are usually visible. A particularly significant example is India, where the Eleventh National Plan (2008-2012) includes 27 time-bound targets, of which 13 can be disaggregated at State level. The targets fall into six categories covering: income and poverty; education; health; women and children; infrastructure; and the environment. Targets include clean drinking water for all by 2009, halving infant malnutrition by 2012, and reducing maternal mortality to one per 1,000 live births by the same year. The approach is highly consistent with the MDG concept.

UNDP also notes the value of the MDGs (or of local adaptations) to advocacy and campaigns for better conditions for the poor. It notes that the UN Secretary-General Kofi Annan, in putting forward the Goals in his 'Road Map for the Implementation of the MDGs' of 2001, had noted that a powerful purpose was 'to mobilise people power in the fight against poverty and inequality'. There is a good deal of anecdotal evidence that in some countries, Indicators drawn from the MDGs have become an increasing focus of civil society campaigning in developing countries. The UN Millennium Campaign is seeing some significant resonance in developing countries (over 116 million people in about 110 countries took part in its 'Stand Up for the MDGs' campaign in 2008), and other advocacy groups such as African Monitor use the MDGs routinely as a basis for campaigning.

Evidence of impact on resource allocation is scarce. The OECD (2007) quote figures from the World Development Indicator database, which suggest that public spending on health in developing countries rose from 2.6 per cent of GDP in 2000 to 2.8 per cent in 2004, and on education from 3.9 per cent to 4.3 per cent. These figures cannot be broken down by subcategory (e.g. basic education), and while the increases are positive, they are in a context of rising expenditure/GDP ratios more generally.

A preliminary conclusion might be that, as with the donors, the MDGs have so far had more influence on political discourse than on resource allocation in developing countries. This is particularly so for documents such as Poverty Reduction Strategy Papers (PRSPs), which are designed in large measure to satisfy the demands of the donor community. However, the increasing use of customised MDG-based outcomes as a basis for local discussion of progress suggests that the potential of the MDGs to change behaviour over time might be significant.

More generally, it seems likely that the MDGs have had some impact, both for donors and for developing countries (including civil society actors as well as the official sector) in the way that issues are framed. As Carol Weiss argued (Weiss 1977), the generalisations that flow from research findings provide decision-makers with a way of framing the issues: the MDGs are an example of an Indicator set that has certainly had some influence of this kind.

\section{Has the influence of the MDGs been constructive?}

The previous section has argued that the influence of the MDGs on real-world behaviour has so far been modest, although it has also pointed to indications that the MDG approach might become more influential over time, both for donors and for developing countries. If this is the case, it is worth examining whether the influence is likely to be constructive or not.

The view of many advocacy groups ${ }^{7}$ appears to be that the MDGs are in general a highly positive advocacy tool, and that substantial revisions (not likely before 2015) would be unwelcome.

Aspects they appreciate include:

The MDGs recognise the multidimensional nature of poverty - as opposed to the more piecemeal declarations of specialist international conferences.

- The MDGs are relatively comprehensible for the non-specialist public.

- The 'parsimony' of the headline MDGs (despite the large number - over 60 - of Indicators) aids comprehension and understanding.

- The period for showing results is neither too short to be credible nor too long to exert pressure.

At the same time there is no shortage of critics of the MDGs, in civil society and academic circles in particular. Key critiques include:

- They are too 'one-size-fits-all' (Vandemoortele 2009)

- They are unrealistically ambitious, at least for many countries (Clemens et al. 2007) 
- They 'ghetto-ise' development as a Southern problem, rather than linking it to Northern lifestyles (Saith 2006). In addition, Goal 8, the main one with an impact beyond developing countries, lacks any deadlines, and consequently the MDGs 'let the donors off the hook'

- They pay too little attention to inequality or to empowerment of the poor (Watkins 2008; Vandemoortele 2009)

- They are 'anti-growth' (Chang 2008)

- Key dimensions of development are omitted (e.g. human rights and other important topics of the Millennium Declaration)

- Many parameters are poorly specified (e.g. the focus on education enrolment without reference to education outcomes, the Indicators on environment and gender).

The energy of the debate on these and other items suggests that, consistently with my comments on impact above, many commentators do see at least the potential of impact, and are concerned that aspects of the MDGs may have negative consequences.

It is hard to say at this stage whether the construction of the MDGs has had any negative consequences in practice. To take an example, it is clear that enrolment in basic education has increased in many African countries with so far quite disappointing results for numeracy and literacy of school leavers, but it is less obvious whether the failure of the relevant MDG to look beyond enrolment can be considered a material cause (as opposed, let's say, to the political attractions of announcing free basic education and the willingness of donors to support it versus the sheer hard graft of training and hiring teachers, revising the curriculum, and putting in place good incentives for learning). Nevertheless, many of the critiques have force, and could and should be attended to in any post-2015 results framework.

\section{What lessons might be drawn for subsequent attempts to define development Goals on an international level after 2015?}

As 2015 approaches, increasing attention is likely to be paid to the question of whether any further MDG-type results framework should be put in place for a future period.

The first key questions are: What would be the purpose of any new framework? Should it continue to be about sustainable, pro-poor development progress (i.e. a core focus on poverty in all its dimensions) or should it be more about how we can collectively mange the planet in the medium term? Clearly, many issues would be common to both, since sustainable poverty reduction requires progress on issues such as climate change and conflict resolution, which would undoubtedly feature heavily in an Indicator set designed to encourage better collective management of the planet, and poverty reduction would surely itself be one issue that better collective management of the planet would necessarily address. However, the choice is a significant one, both on substance (e.g. Would the latter approach in practice marginalise the poverty agenda?) and on process (How would an Indicator set for better planetary management something affecting a huge range of agencies and interests - be negotiated?). This issue parallels the question of whether the 'aid business' will increasingly mutate into a 'global public goods business', something already highlighted in the Climate Change negotiations.

Any post-2015 framework should maintain good features of the MDGs including:

- Parsimony at Goal level, and to the extent possible also at Target level, probably using a structure similar to that of the MDGs, with no more than ten top-line Goals, ${ }^{8}$ ideally few if any more Targets (maybe 25 should be the upper limit) than in today's MDGs, but perhaps rather more Indicators (e.g. 80 in place of the current 60), in order to respond to reasonable demands for somewhat more comprehensive measurement of progress in addressing poverty

- A time-span of around 15 years for reaching the Targets ${ }^{9}$

- A process for updating the Targets and Indicators that is sufficiently tightly managed to guarantee stability in the core design, while allowing for modest flexibility. As with the present set, Goals themselves, which would be written as broad and unquantified objectives, should not be altered during the life of the framework

- Comprehensible language, particularly at Goal level.

However, the framework should also respond to valid critiques. Among these I would put particular weight on the following: 
1 Targets for desired outcomes should be set at either global level or for developing countries as a group,${ }^{10}$ not at individual country level, although the 'global' targets could and should be used to encourage more rapid progress at country level. All countries should be invited (as was done at the Jomtien Education Conference of 1990) to set their own national targets for each goal, ideally but not necessarily for the same period of 15 years, and ideally through some bottom-up process. Some regions or sub-regions might choose to do likewise. It is interesting in this connection to note the rise of more community-based setting of outcome frameworks in many countries, as demonstrated at the OECD Global Forums on Measuring the Progress of Societies. Such approaches could very well complement a continued set of internationally agreed Goals and Targets.

2 The global targets should be carefully based on evidence of current rates of progress. They should be stretching but not unachievable at 'global' level.

3 While a focus on reducing and eliminating absolute poverty should be kept, relative poverty should be recognised more clearly as an issue. Targets and Indicators should therefore make transparent what is happening at each income quintile for the parameter concerned (Jan Vandermoortele has suggested ways of weighting progress at each quintile to bring this information to a single number, which could also be a way of ensuring that there is no bias towards progress for those just below any Target at the expense of those much further from it). Gender disaggregation should also be displayed internationally, as it theoretically should be at present, ${ }^{11}$ but too seldom is in MDG reports. At country level, there should be encouragement to disaggregate data in other relevant ways, for example by province.

4 The dimension of human rights should be included, based on the Millennium

Declaration. There should certainly be a Goal in this area, and ongoing work on Indicators (see e.g. Alkire 2007) (including on empowerment) should be pursued with a view to devising some meaningful Target at global level.
5 There should at least be Indicators on the productive sector and on economic infrastructure. A Goal for greater 'connectivity', incorporating Targets on access to core infrastructure services such as water (already included), telecommunications (partially covered in Goal 8), power and transport (illogically excluded), should be considered.

6 Poorly specified Targets in the present set should be looked at critically. These certainly include education, gender and environment (where the outcome of Climate Change negotiations will need to be reflected in some appropriate way). The relevant policy communities should make proposals in the light of some upfront guidance (including on points 1-3 above) so that such proposals are consistent with the overall architecture.

7 The present Goal 8 needs radical revision. Some of its elements could be dropped or moved elsewhere (e.g. ICT to the separate 'connectivity' Goal mentioned above). The references to the problems of particular groups of developing countries could be dealt with by more thoroughgoing disaggregation of reporting of each Target and Indicator. But the concept of a Goal on the enabling environment for poverty reduction makes sense and should be kept. What is harder to agree on is Targets in this area, not least given the increasing significance of the policies of major middle-income countries to sustainable pro-poor growth in a 'G20 World'. Again, the approach might be to set global targets for areas such as trade openness and concessional resource transfer, leaving individual countries (certainly including all G20 members and all OECD and EU members) to determine what they will specifically commit to, enabling peer pressure to be maintained on laggards within each grouping, while recognising that it would be unreasonable to demand the same degree of trade openness or resource transfer for countries whose economic situations are objectively very different.

\section{Conclusion}

Indicator sets such as the MDGs should not be oversold as some sort of magic bullet to accelerate the achievement of desirable Targets. All such achievements require hard work, 
commitment and financial and human resources. But they can affect the way people think, and over time that influence may well affect how people and institutions behave. The experience so far with the MDGs suggests that an investment in an improved set of Goals, Targets and Indicators for perhaps a further 15-year period after 2015 would be worth making. It will probably be more difficult to develop a consensus on the structure and content of such a set than was the case in 2000-01, in a world very different from that in which the original MDGs were

\section{Notes}

1 See the 56th General Assembly resolution GA/9999 Plenary, 14 December 2001, 86th Meeting.

2 The Group, set up in 2002, includes the UN Secretariat, a number of UN agencies, the International Monetary Fund (IMF), International Bank for Reconstruction and Development (IBRD), Organisation for Economic Co-operation and Development (OECD), national experts from statistical offices and representatives of other organisations concerned with the development of data for the MDGs.

3 The DFID White Paper and the Conservatives' Green Paper of July 2009 both have a strong focus in this direction, while also paying attention to the issue of progress against the MDGs.

4 The Global Fund to Fight AIDS, Tuberculosis and Malaria was established in 2002; the Global Alliance on Vaccines and Immunisation was established in 1999, but although this preceded the Millennium Declaration and the MDGs, this was well after the OECD/DAC had promulgated the International Development Targets, which had objectives for reducing child mortality identical to the MDGs, and indeed drawn from UN Summits of the early 1990s.

5 This became an area of specific attention in DFID's then Asia Division in the early 2000s, conceived and put in place. It is therefore desirable that informal discussion of options with as wide a group of interested parties as possible should be encouraged. Before long, an international process - presumably under the auspices of the UN - will need to be put in place, in a way that does not distract attention from the need to make rapid progress towards the present Goals by 2015. This article suggests some possible substantive changes in the present MDG framework that any such process could consider.

for example. In September 2009, UN

Secretary-General Ban Ki-Moon and France's First Lady, Carla Bruni-Sarkozy, joined to promote a campaign to halt all mother-tochild transmission of HIV/AIDS by 2015.

6 See for example, IDS Bulletin 40.4.

7 This was clearly stated, for example by both Northern and Southern advocacy groups at a DFID Seminar on the future of the MDGs in March 2009.

8 The discussion below proposes Goals for both Rights and for Connectivity, which would represent a net addition of two. This might however be offset by a rationalisation of the health Goals, while maintaining the present number of health Targets.

9 The MDGs were agreed with, in effect, a 15year time horizon, complicated however by a baseline implicitly set ten years earlier, something that there is no case to repeat.

10 'Developing countries' is a term of very modest usefulness, given the disparities among them. However, it is difficult to see any UN-endorsed process using a different categorisation, short of universal applicability, although recognised sub-categories such as the Least Developed and the Small Island Developing States will no doubt (as in Goal 8) receive some specific recognition.

$11 \mathrm{Urban} / \mathrm{rural}$ disaggregation is also theoretically written into the MDG framework, but even less often displayed. 


\section{References}

Alkire, Sabina (2007) The Missing Dimensions of Poverty Data, Oxford: Oxford Development Studies

Chang, Ha-Joon (2008) 'Comments on Jeffrey Sachs' Proposals for a Bretton Woods 2', The Guardian, 22 October

Clemens, Michael; Kenny, Charles and Moss, Todd (2007) 'The Trouble with the MDGs: Confronting Expectations of Aid and Development Success', World Development 35.5: 735-51

Fukuda-Parr, S. (2008) Are the MDGs Priority in Development Strategies and Aid Programmes? Only Few Are!, Brasilia: UNDP International Poverty Centre (IPC)

Manning, Richard (2009) Using Indicators to Encourage Development: Learning Lessons from the $M D G s$, Copenhagen: Danish Institute for International Studies (DIIS)

OECD (2007) 'Development Cooperation Report', Journal on Development 9.1: 26-7 and Table 1.3
OEGD DAC (2004) 'Development Cooperation Report', OECD DAC Journal 5.1: 37-40

Saith, Ashwani (2006) 'From Universal Values to Millennium Development Goals: Lost in Translation', Development and Change 37.6: 1167-99

UNDP (2009) Beyond the Midpoint: Accelerating Support for MDG Achievements, New York: United Nations Development Programme Vandemoortele, Jan (2009) 'The MDG

Conundrum: Meeting the Targets Without Missing the Point', Development Policy Review 27.4: $355-71$

Watkins, Kevin (2008) The Millennium Development Goals: Three Proposals for Renewing the Vision and Reshaping the Future, Paris: UNESCO

Weiss, C.H.H. (1977) 'Research for Policy's Sake: The Enlightenment Function of Economic and Social Research', Policy Analysis 3: 531-45 